\title{
A home for the mighty mouse
}

\author{
With the aid of private health organizations and the Howard Hughes Medical Institute, the Jackson Laboratory will \\ become the world's clearinghouse for transgenic and knockout mice - at a reasonable price.
}

Ar last, it is the decade of the mouse. Whereas once finding a mouse model for disease was a matter of serendipity, mice now can be created to a researcher's specifications. In the mid-1980s the "Harvard mouse", a transgenic creature that is susceptible to breast cancer, was developed under a research agreement with the DuPont Company that holds the patent.

Then there were 'knockout mice' a variation on the theme of creating (rather than waiting for nature to reveal) research-friendly mice from the laboratory of Mario

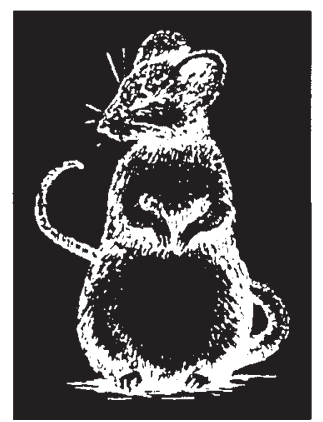

Capecchi at the Howard Hughes Medical Institute at the University of Utah, who discovered that mediating homologous recombination at the early $S$ phase of the cell cycle could enable him to knock out or disable a gene at will. One recent result is a mouse with developmental defects of the ear, cranial nerves and hindbrain, all because of a targeted disruption of the homeobox gene Hox-1.6 (Nature 355, 516-520; 1992).

Since then, there has been a veritable population explosion of transgenic and knockout mice. There is a mouse whose cystic fibrosis (CF) gene has been knocked out, making it the first animal model for that common genetic disease. An Apoe mouse that develops severe arterial plaque, even on a low-fat diet, is now available for use in research. And, perhaps most important, researchers, beginning with Allan Bradley's laboratory at Baylor College of Medicine in Houston, have introduced a null mutation for the p53 gene in mice, showing that its absence predisposes mice to neoplastic disease by the age of six months (Nature 356, 215-221; 1992).

As a result of these and other studies, says Kenneth Paigen, director of the Jackson Laboratory in Bar Harbor, Maine, "we are in the early stages of the most profound scientific revolution yet seen". Since 1929, the Jackson Laboratory has identified through careful screening and inbreeding some 1,700 genetically special strains of mice. But now, says Paigen, "with transgenic and knockout mice we suddenly have the ability to create tailor-made mammalian models of human disease which offers the opportunity to study complex physiological phenomena, such as the nervous and immune systems, AIDS, and cancer, as never before. And we need to look at mice because they are a remarkable experimental surrogate for us, which is what medical research is really all about."

And so it seems that the scientific celebrity of the much studied Escherichia coli, of Caenorhabditis elegans (that intellectually beautiful worm), of the sturdy fruitfly and even the newly popular zebra fish is being eclipsed.

The decade of the mouse is here, but it did not take much prescience to see it coming. Ever since the recombinant DNA revolution made biological science a business by giving biologists products (such as drugs) and research tools (such as enzymes and mice) that they could sell, patent lawyers, stock traders and entrepreneurs have been avidly watching in the wings. In the mouse business, DuPont was first with the Harvard Myc mouse and a patent with a set of royalty payments and so-called 'reach-through' clauses affecting the use of progeny of breeding pairs that gave the traditional notion of the free exchange of scientific material among researchers a new meaning. Others followed suit, most notably GenPharm of Mountain View, California, which acquired from the Baylor laboratory the right to breed, sell (at around $\$ 100$ a mouse) and receive fees on the progeny of breeding pairs of Bradley's p53 knockout.

"The GenPharm situation got everyone very heated", says Harold Varmus of the University of California at San Francisco (and director-designate of the US National Institutes of Health). At the Mouse Molecular Genetics meeting at Cold Spring Harbor in August 1992, he chaired what is politely referred to as a debate about what to do. "Ken Paigen gave an impassioned speech about the importance of free exchange", he recalls. Varmus then organized a more formal, less confrontational meeting on "Sharing laboratory resources" at the US National Academy of Sciences. Transgenic and knockout mice are expensive to create and costly to maintain (between $\$ 50,000$ and $\$ 100,000$ a year). They are therefore virtually out of reach of many researchers if they have to be purchased from commercial sources expecting (reasonably) to make a profit on their sales.

The NIH responded by putting out what it says is a once-only request for applications (RFA), offering to establish a national resource for transgenic [and knockout] ani- mals. That grant should be awarded within a couple of months.

Meanwhile, Paigen started seeking funds from private health organizations for an 'induced mutant resource' at the laboratory in Bar Harbor. Remarkably, he struck a chord. The March of Dimes, which supports research on birth defects, made the first contribution, followed by the American Cancer Society, the American Heart Association, the Cystic Fibrosis Foundation and the Multiple Sclerosis Society. Now, in an act of unprecedented unity, these groups are urging larger charities, such as the Wellcome Foundation, to join them. Happily, the Howard Hughes Medical Institute made a commitment of $\$ 1.2$ million spread over three years and the resource is up and nearly running.

The Jackson Laboratory, with its proven capacity for breeding disease-free animals and for embryo cryopreservation, is distributing the CF mouse, and the Min mouse, which gets the equivalent of human colon cancer. And it is preparing to distribute a p53 mutant from the laboratory of Tyler Jacks at the Massachusetts Institute of Technology (MIT). (To preserve a disease-free colony, breeding pairs of $\mathrm{p} 53 \mathrm{~s}$ from MIT will not be accepted. Only hysterectomyderived pups will be admitted to the breeding colony.) Unlike the GenPharm $\mathrm{p} 53$, the Jax p53 mouse will cost about $\$ 60$ a breeding pair, once there are enough of them. John Sharp, head of the induced mutant colony, says there is already a waiting list. The laboratory hopes to 'import' 50 different induced mutants in its first year of operation, eventually taking as many as 100 different breeding pairs. But even with solid funding and laboratory expansion, that may be the annual limit. A special admissions committee has therefore been established to evaluate candidate mice and select those that will be of greatest value to the scientific community. Getting one's mouse into the Jax colony may one day be as competitive as getting a child into an exclusive nursery school.

With subsidies from private foundations and health charities, bolstered by underwriting from the NIH (if the laboratory wins the grant), the not-for-profit Jackson Laboratory can afford to make these invaluable mouse resources affordable to others. In the process, it will not only advance the cause of science but also bring back an earlier day when science and profit did not necessarily go hand in hand.

Barbara J. Culliton 